\title{
Enfermagem pré-profissional no Brasil: questões e personagens
}

\author{
Recebido em: 18/05/2010 \\ Aceito em: 21/03/2011
}

\author{
Taka Oguisso \\ Paulo Fernando de Souza Campos ${ }^{2}$ \\ Almerinda Moreira ${ }^{3}$
}

O presente artigo recupera experiências efetivadas por homens e mulheres em contextos distintos da história da enfermagem pré-profissional brasileira, anterior à institucionalização da formação acadêmica. Pretende-se atualizar conteúdos específicos, recuar o tempo histórico e evidenciar personagens que atuaram no âmbito do cuidar. O objetivo deste trabalho é contribuir para o reconhecimento de ações derivadas do cuidado pré-profissional, desvelando questões pertinentes à pesquisa em enfermagem. Acredita-se que os conteúdos relativos ao período pré-profissional transformam interpretações existentes sobre as origens do cuidado no Brasil, cujas matrizes históricas fundamentam práticas e teorias contemporâneas (humanização, equidade), indicativos seguros da utilidade da análise histórica em relação ao desenvolvimento da profissão.

Descritores: História da Enfermagem, Cuidadores, Pesquisa em Enfermagem.

\section{Pre-professional nursing in Brazil: issues and characters}

This article recovers past experiences by men and women within distinct contexts of the Brazilian pre-professional nursing history, prior to the academicals education institutionalization. This paper aims to up to date specific contents, go back in the historical time and to evidence who have worked within caring scope and to contribute for the recognition of derived actions in the pre-professional caring scope, showing issues related to nursing research. It is believed that contents related to the pre-professional period may change existent interpretations on the caring origins in Brazil, whose historical sources are based on contemporaneous practices and theories (humanization, equity) may safely indicate the utility of the historical analysis in relation to the development of the profession.

Descriptors: Nursing History, Carers, Nursing Research.

\section{Enfermería pre-profesional en Brasil: cuestiones y personajes}

El presente artículo recupera experiencias vividas por hombres y mujeres en contextos distintos de la historia de la enfermería pre-profesional brasileña, anterior a la institucionalización de la formación académica. Los objetivos intentan actualizar contenidos específicos, retroceder en el tiempo histórico y evidenciar personajes que actuaron en el ámbito del cuidar. El intento es contribuir para el reconocimiento de las acciones derivadas del cuidado pre-profesional desvelando cuestiones pertinentes a la investigación en Enfermería. Se cree que los contenidos relativos al período pre-profesional transforman interpretaciones existentes sobre los orígenes del cuidado en el Brasil, cuyas bases históricas embasan prácticas y teorías contemporáneas (humanización, equidad) indicativos seguros de la utilidad del análisis históricos en relación al desarrollo de la profesión.

Descriptores: Historia de la Enfermería, Cuidadores, Investigacíón en Enfermería.

\section{INTRODUÇÃO}

N os primórdios da humanidade, na pré-história, os membros da incipiente sociedade vagavam comportando-se como caçadores e coletores. Essa instintiva aventura de sobrevivência era, com certeza, acompanhada de inúmeros riscos de morte e ferimentos. Quando acontecia um acidente ou doença, o instinto gregário e a própria vida nômade obrigavam-nos a receber cuidados possíveis no próprio local do evento ou em abrigos que serviam de morada. Historicamente, pode-se dizer que os cuidados dispensados a uma pessoa na própria habitação é uma das mais antigas - ainda que rudimentares - formas de atenção ao ser humano.

A perspectiva apontada permite reiterar que "os cuidados existiram desde que surgiu a vida, uma vez que seres humanos - como todos os seres vivos - sempre precisaram de cuidados"; vale dizer, "cuidar é o ato de vida que tem como fim, primeiro e antes de tudo, permitir que a vida continue a desenvolver-se e, assim, lutar contra a morte: morte do indivíduo, morte do grupo, morte da espécie"(1).

Na trajetória evolutiva da sociedade, a ação de cuidar ou

1 Enfermeira. Professora titular da Escola de Enfermagem da Universidade de São Paulo/EEUSP. Líder do Grupo de Pesquisa História e Legislação da Enfermagem - ENO/EEUSP. E-mail: takaoguisso@usp.br.

2 Historiador. Doutor em história. Programa de pós-doutorado da EEUSP. Pesquisador do Grupo de Pesquisa História e Legislação da Enfermagem - ENO/EEUSP. Bolsista Fapesp. 3 Enfermeira. Doutora em enfermagem. Professora adjunta da Escola de Enfermagem Alfredo Pinto da Universidade. Pesquisadora do Laboratório de Pesquisa em História da Enfermagem - Laphe/Unirio. 
"tomar conta" de pessoas, no sentido de ajudá-las a cuidar de si e de atender a suas necessidades vitais, confunde-se no tempo com o trabalho da mãe que nutre seus filhos e deles cuida. Da mesma forma, a mulher deveria cuidar de outras pessoas dependentes, como idosos, feridos e doentes. A proteção materna instintiva, nesses termos, pode ser considerada como a primeira forma de manifestação de cuidados do ser humano com seus semelhantes.

À medida que grupos humanos abandonavam o nomadismo e se fixavam em determinado território, formando os primeiros assentamentos humanos, surgiam primitivas organizações sociais, nas quais homens e mulheres assumiam funções distintas nesse embrião de sociedade. Homens dedicavam-se à caça e pesca, com todos os riscos inerentes a essas tarefas, e mulheres voltavam suas ações para as lides domésticas. Ambos, porém, dedicados a
"No período pré-cristão, especialmente na Grécia, enfermos acorriam aos templos para pedir ajuda aos deuses e lá permaneciam" orfãos e pobres, para deles cuidar, iniciando, muitas vezes, ordens e congregações religiosas. Pessoas que assim agiam, homens e mulheres, ingressavam em mosteiros com o objetivo precípuo de se dedicar a essas atividades ${ }^{(2)}$.

O presente texto pretende atualizar conteúdos pouco conhecidos ou estudados, qual seja, os precursores da enfermagem brasileira. A proposta é divulgar a ação de pessoas que, em seu tempo e nas circunstâncias e condições existentes, procuravam atender às necessidades humanas, consubstanciando o que se convencionou chamar de enfermagem pré-profissional. Tratava-se, em outras palavras, de um tipo de cuidado baseado mais na intuição e no espírito de servir do que em ganhos materiais ou até sociais, mesmo porque não havia qualquer tipo de instrução formal capaz de qualificar o trabalho do cuidador. Este estudo focaliza personagens que cuidar, isto é, "manter a vida dos seres humanos com o objetivo de permitir a reprodução e a perpetuidade da vida do grupo"(1).

No período pré-cristão, especialmente na Grécia, enfermos acorriam aos templos para pedir ajuda aos deuses e lá permaneciam. Apolo, grego venerado como deus da medicina, assim como seu filho Esculápio, cuja representação - homem com cajado no qual uma serpente está enrolada - permanece simbolizando esse campo do conhecimento. Templos dedicados a esses deuses começaram a surgir, segundo escritos de Homero, cerca de 1.100 anos antes de Cristo.

No ano 460 a.C., Hipócrates, filho de médico, criado no templo de Esculápio, passou a estudar o lado biológico do indivíduo, baseando-se em experiências e observações críticas acerca da natureza e dos fenômenos que acometiam órgãos humanos. Assim, dissociou a medicina de forças sobrenaturais e superstições, ensinando que os que se dedicassem a essa tarefa deveriam seguir um rígido compromisso, ainda hoje utilizado e conhecido como Juramento de Hipócrates. O momento mais solene da formatura de médicos é justamente aquele em que os formandos juram praticar a medicina seguindo preceitos éticos em sua totalidade. Por tudo isso, Hipócrates é considerado o "Pai da Medicina"(2).

Com o advento do cristianismo, a ação de cuidar de doentes, idosos, crianças e pobres adquiriu relevo e importância. Tornou-se a forma que muitas pessoas, não apenas da aristocracia e nobreza, adotavam para dedicar sua vida à obra de caridade como maneira de imitar o próprio Cristo. A história da humanidade relata que pessoas destinaram suas casas ou palácios para receber doentes,

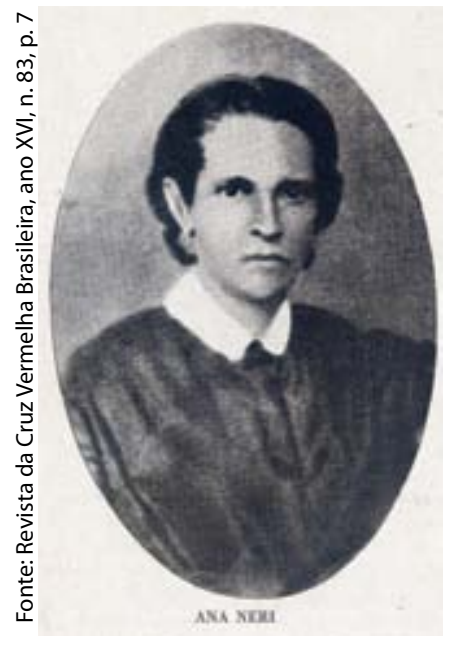

Anna Justina Ferreira Nery, por sua singular manifestação na Guerra do Paraguai, tornou-se patrona da enfermagem brasileira. Seu nome evoca um dos principais espaços formadores da arte e ciência do cuidado da América Latina. prestaram cuidados baseando-se em um saber constituído pela prática, e não pela formação profissional.

\section{Precursores da enfermagem brasileira}

No início do período republicano, a enfermagem profissional foi se impondo como elemento coadjuvante obrigatório no processo de tratamento e cura, o que levou ao desenvolvimento de novos modelos de prestação de serviços na área da saúde e ao surgimento de um novo perfil de enfermeiros, a partir da qualificação e sistematização dos conhecimentos e técnicas

Há ainda certo olhar de indiferença ou desconfiança em relaçãoàs pessoas que se dedicaram ao cuidado de doentes ou feridos, crianças ou idosos nesse contexto da pré-profissionalização, inclusive os que deixaram seu nome na história do Brasil. Contudo, reais ou ficcionais, autoridades e mesmo a literatura Ihes atribuem o título de enfermeiro ou enfermeira, como os casos de Francisca de Sande, frei Fabiano de Cristo, padre José de Anchieta, Anna Nery e Procópio José Gomes Valongo, personagem do conto "O Enfermeiro", de Machado de Assis ${ }^{(4)}$.

Collière $^{(1)}$, assim como alguns outros estudiosos, referendam a diferença conceitual entre ofício e profissão. Ofício relacionava-se a um tipo de serviço prestado à comunidade, sem definição de regras. Profissão era uma atividade composta de um corpo de pessoas que obtiveram um título conquistado pela formação profissional com vistas a exercer uma mesma atividade, organizadas em associações profissionais e dotadas de um código de ética e deontologia. De fato, a enfermagem profissional é aquela atividade exercida por pessoas que passaram por um praticados nessa área(3). 
processo formal de aprendizado, com base em um ensino sistematizado, com currículo definido e estabelecido em ato normativo e que, ao término de um período, recebem diploma e titulação específica ${ }^{(5)}$.

O jesuita padre José de Anchieta (1534-1597) merece ser citado como o mais antigo precursor da enfermagem préprofissional brasileira, pois atuou como professor, médico e enfermeiro, conforme relatam Lycurgo Santos Filho ${ }^{(6)}$ eWaleska Paixão ${ }^{(7)}$. Anchieta nasceu em Tenerife, uma das Ilhas Canárias, Espanha. Após estudar em Coimbra, ingressou na Companhia de Jesus, em 1551, e dois anos depois foi enviado ao Brasil com a comitiva de Duarte da Costa, segundo governadorgeral, com o intuito de catequizar índios. Em 1554, fundou a cidade de São Paulo de Piratininga, juntamente com o padre Manoel da Nóbrega. Além da catequese, o padre Anchieta acudia a duas necessidades do povo, ou seja, educação e saúde, usando plantas medicinais em técnicas aprendidas com indígenas e outras terapêuticas trazidas de Portugal, adaptadas ao clima, aos costumes e às doenças mais comuns do novo mundo. Também teve de enfrentar as doenças introduzidas posteriormente no Brasil com a chegada de naus portuguesas, cujos tripulantes, homens e mulheres degredados, transmitiam doenças, dizimando populações inteiras de índios que viviam na costa brasileira ${ }^{(6,7)}$.

Desde as primeiras tentativas de colonização pelos portugueses, a abertura de Santas Casas de Misericórdia estava prevista. Frei Miguel de Contreras, religioso espanhol, com o apoio da rainha Leonor de Alencastre, criou a primeira Santa Casa em Lisboa, em 1498, como espaço voltado à prática de obras de misericórdia. O impulso levou muitos associados da Confraria da Misericórdia a exercer atividades de atenção a enfermos, por caridade ou espírito de solidariedade. A partir da primeira Santa Casa, pequenos núcleos e povoados quiseram ter seus respectivos espaços destinados a atender pessoas acometidas de doenças e outros problemas de saúde ${ }^{(8)}$.

O primeiro hospital brasileiro foi justamente a Santa Casa de Misericórdia de Santos, criada en 1543, por Brás Cubas. Nesse local, enfermos eram cuidados por religiosos da Companhia de Jesus ou da Ordem dos Jesuítas. Não existem dados substanciais sobre como era praticada a enfermagem nas primitivas Santas Casas, mas supõe-se que os jesuítas assumiam, eles próprios, os trabalhos gerais de enfermagem, fazendo-se auxiliar pelos índios e africanos escravizados, a quem ensinavam como ajudar enfermos e outros trabalhos em torno do cuidado (limpeza, ordem, entre outros).

O Brasil, como colônia de Portugal, logo implantou a ideia e outras Santas Casas se sucederam, como as de Salvador, Rio de Janeiro, São Paulo e Vitória, todas no século 16. As demais vieram nos séculos seguintes, em diferentes pontos do país, totalizando mais de 400 Santas Casas, que funcionam como hospitais, com recursos obtidos do Ministério da Saúde.
Destacadamente, grande parte dos serviços foi entregue, em geral, a religiosos, especialmente Filhas da Caridade, de São Vicente de Paulo, que aportaram no país em $1852^{(9)}$.

Contudo, a história permite afirmar que, no século 17, Francisca de Sande, filha dos portugueses Francisco Fernandes do Sim e Clara de Sande, dedicava-se ao cuidado, atuando de modo decisivo na atenção a pessoas necessitadas e convalescentes, vivendo em Salvador, Bahia, no tempo em que a cidade era a capital do país. Não querendo dedicar-se à vida religiosa, casou-se com Nicolau Aranha Pacheco, considerado um dos mais prestativos cidadãos da Bahia seiscentista. Em 1631 , ele ingressou na milícia como soldado. Como capitão da infantaria, em 1638, distinguiu-se no combate contra as forças holandesas comandadas por Maurício de Nassau. Ao falecer, em outubro de 1679, deixou viúva Francisca de Sande, com quem tivera quatro filhos(10).

Em dezembro de 1685, o Brasil foi atingido por uma avassaladora epidemia de febre amarela. Conhecida como"mal da bicha", a doença causou, em Pernambuco, a morte de mais de 2 mil pessoas. Em abril de 1686, a doença alastrava-se para a antiga capital do Brasil (Salvador, Bahia), onde houve "estragos terríveis em grande parte porque a gente cativa era deixada em barracões imundos pelos traficantes". As vicissitudes da epidemia tornavam patente que essa era resultante da falta de um serviço de saúde pública e higiene da cidade, fatores que contribuíam para sua disseminação(11).

Um dos primeiros passos de Francisca de Sande foi fazer de sua casa um hospital, recolhendo doentes que não cabiam na Santa Casa de Misericórdia, preparando-Ihes alimentos, ministrando medicamentos e outros cuidados com o asseio corporal, roupas, camas e outros fatores considerados fundamentais no combate à doença. No jornal $A$ Tarde, Afonso Costa referia que, em tão grande calamidade, dona Francisca, "a carinhosa enfermeira, senão a pioneira dessa missão sublime no Brasil, em toda parte era encontrada com seus escravos a providenciar socorros e a animar a população que se estorcia em dores de fazer cortar o coração". Suas ações mereceram agradecimento do rei, dom Pedro II, da dinastia de Bragança e $23^{\circ}$ rei de Portugal. Francisca de Sande faleceu no dia 29 de outubro de $1702^{(10,12)}$.

Outro personagem que se dedicou ao cuidado foi frei Fabiano de Cristo (1676-1747), religioso, franciscano, considerado também precursor da enfermagem brasileira. Nasceu em Soengas, no norte de Portugal, e foi chamado João Barbosa, filho de Gervasio Barbosa e Senhorinha Gonçalves. Teve vida simples e pobre, sem grandes contatos com livros. Inicialmente, dedicou-se a atividades comerciais, e, com o intuito de enriquecer, veio para o Brasil, estabelecendo-se na cidade de Mariana, Minas Gerais. Em 1704, fixou residência em Parati, Rio de Janeiro, cidade na qual passou a ajudar o pároco, sentindo que poderia dedicar-se mais à vida espiritual. 
Ingressou na ordem franciscana em novembro de 1704 e adotou o nome de Fabiano de Cristo.

No fim de 1705, foi transferido para o Convento de Santo Antônio, Rio de Janeiro, onde atuava como porteiro. Finalmente, em 1708, recebeu a incumbência de tomar conta da enfermaria ${ }^{(7)}$. Mesmo sem preparação específica - algo inexistente no Brasil, à época -, frei Fabiano, com grande esforço pessoal e dedicação, procurava atender, ainda que empiricamente, necessidades de enfermos que estavam sob seus cuidados, permanecendo vigilante noite e dia, pois dormia em qualquer lugar dentro da enfermaria. Permaneceu cerca de 38 anos exercendo a atividade, cuidando de doentes e idosos, apesar dele mesmo sofrer de erisipela crônica nas pernas, o que dificultava a movimentação, especialmente em sua função de enfermeiro(13).

Anna Nery, a mais célebre dentre os precursores da enfermagem brasileira, era baiana, filha de Luisa Maria das Virgens e José Ferreira de Jesus. Nascida em 13 de dezembro de 1814, em Cachoeira, faleceu em 1880. Foi casada com um oficial da Marinha, capitão de fragata, Isidoro Antonio Neri, com quem teve três filhos: Isidoro Antonio, Antonio Pedro e Justiniano. Ficou viúva em 1844, quando tinha apenas 30 anos de idade.

Em 1864, Anna Nery residia em Salvador, Bahia, quando começou a Guerra do Paraguai (1864-1870). Dois de seus irmãos e seus filhos decidiram partir para a luta em defesa do país. Embora estivesse com 50 anos de idade, Anna Nery resolveu oferecer-se ao presidente da província (o correspondente a um governador do estado) para cuidar de soldados e feridos de guerra, uma vez que seus filhos lutavam no Paraguai. Imbuída do desejo de também contribuir para a defesa da pátria, partiu para a guerra no dia 13 de agosto de 1865, com um exército de voluntários, mesmo não tendo resposta oficial a sua solicitação.

Encontrava-se no front de batalha quando recebeu nomeação como enfermeira para servir no Paraguai. Sabese que a atuação de Anna Nery foi incansável no cuidado de feridos, ministrando medicamentos, proporcionando alívio e conforto aos doentes por aproximadamente cinco anos em diferentes lugares, como Curupaiti, Humaitá, Assunção e Corrientes. Retornou à Bahia em julho de 1870, trazendo três órfãos de soldados mortos, que educou como seus filhos. Foi homenageada pelo imperador dom Pedro II com o título de "Mãe dos Brasileiros", embora ela socorresse também não brasileiros, bastava estarem feridos. Recebeu também medalhas de mérito e pensão anual.

Seu retrato, pintado a óleo por Vitor Meireles, em tamanho natural, ficou exposto na sede da Cruz Vermelha Brasileira, Rio de Janeiro, como prova de gratidão. Mais tarde, proclamada a República, em 1926, foi novamente homenageada, significativamente pela Escola de Enfermeiras do Departamento Nacional de Saúde Pública, que recebeu seu nome, passando a denominar-se Escola de Enfermeiras D. Ana Néri, hoje pertencente à Universidade Federal do Rio de Janeiro. Anna Nery faleceu em 20 de maio de 1880, aos 66 anos de idade, sendo sepultada no Cemitério São Francisco Xavier. Em 1956, foi erigida uma estátua em praça pública em sua homenagem, localizada em frente ao edifício-sede da Cruz Vermelha Brasileira, Rio de Janeiro(7). Em 1960, foi instituída oficialmente, no Brasil, pelo presidente da República, Juscelino Kubistchek, a Semana da Enfermagem, marcando-se seu início em 12 de maio, data de nascimento de Florence Nightingale e terminando em 20 de maio, data da morte de Anna Nery.

Neste sentido, ressalta-se que, nos períodos históricos identificados como Brasil Colônia (1500/1822) e Brasil Império (1822/1889), o cuidado também foi exercido por homens e mulheres comuns, escravizados ou não, como o caso das amas-de-leite, babás e mães pretas, que se dedicavam ao cuidado de crianças, idosos, gestantes e parturientes. Sua história foi por muito tempo negligenciada, pouco analisada, constituindo-se, portanto, em um amplo campo de estudos em história da enfermagem. Personagens de uma história em construção, chamados enfermeiros, esses homens e mulheres merecem respeito e reverência por terem se dedicado, de alguma forma, a feridos e doentes, crianças e idosos. Recuperar a memória esquecida desses personagens implica reconsiderar a história dos cuidados no Brasil(13,14).

\section{Profissionalização da enfermagem brasileira}

A enfermagem encontrava-se socialmente decadente no início do século 19 em praticamente todos os países do mundo. Sua prática ressurgiu pelas mãos de Florence Nightingale (1820/1910) como uma nova representação, ou seja, fundada na humanidade, tecnicidade, modernidade, intelectualidade, cientificidade e até mesmo aristocracia e nobreza de idealismo e arte.

Com a evolução das ciências e o progresso da tecnologia, a assistência à saúde começou a ser transferida para instituições hospitalares, consideradas o ambiente mais seguro e apropriado para a prestação dos serviços aos que deles necessitavam. Com a alocação de recursos cada vez maiores e mais sofisticados, a assistência hospitalar tornouse gradativamente mais dispendiosa e menos acessível à população, especialmente à rural ou mesmo à população urbana carente, continuadamente desassistida.

Contemporaneamente, é possível afirmar que, no Brasil, a profissionalização da enfermagem teve início com a fundação da Escola Profissional de Enfermeiros e Enfermeiras, no Hospital de Alienados, em 1890, atual Escola de Enfermagem Alfredo Pinto, da Universidade Federal do Estado do Rio de Janeiro (Unirio). Instituições privadas somaram-se a esse esforço oficial do governo, criando-se escolas e cursos abertos 
como os realizados pelo Hospital Samaritano, em 1894, na cidade de São Paulo; Cruz Vermelha Brasileira - Filial Estado de São Paulo, em 1912. Essa escola, no ano de 1914, ofereceu curso para enfermeiras voluntárias e, em 1916, curso para enfermeiras profissionais, ambos na cidade do Rio de Janeiro. Também no Rio de Janeiro, a Policlínica Botafogo, de 1917, encontra-se entre outras tantas experiências que extrapolaram a oficialidade dos acontecimentos, da qual a história se serve para compreender o passado.

Vale destacar que diferentes escolas e cursos antecederam a fundação da Escola de Enfermeiras do Departamento Nacional de Saúde Pública, em 1923, que, em 1926, passou a ser denominada Escola de Enfermeiras D. Ana Néri, atualmente Escola de Enfermagem Anna Nery, da UFRJ. Espaço de formação profissional, implantou oficialmente o sistema de ensino anglo-americano, a versão americana do Modelo Nightingale, pois o sistema inglês, considerado puro, havia sido implantado por enfermeiras inglesas no Hospital Samaritano, na cidade de São Paulo, em 1895. Nesse sentido, cabe destacar a diferença entre o sistema Nightingale anglo-americano e o sistema Nightingale puro, pois a versão americana sempre buscou alocar o ensino em universidades e o sistema inglês alocava dentro de hospitais.

Todavia, no fim do século 19 e início do século 20, não era comum às pessoas acorrerem ao hospital em caso de doença ou mesmo de nascimento, pois era prática corrente que essas se recolhessem a seus aposentos e lares, sendo cuidadas por alguém da família ou por escravas, que atuavam como parteiras. Assim, apesar das escolas existentes, a enfermagem ainda era exercida em grande parte por pessoas não preparadas profissionalmente, conforme descrito por Araújo (3), que mostra, através de anúncios de jornais da época, quem de fato exercia a enfermagem, como demonstra o anúncio do Diário Popular ao divulgar a seguinte nota: "Enfermeiro: uma pessoa que tem prática de enfermeiro deseja empregar-se em alguns dos hospitais, casas de saúde; dá fiança idônea de seu comportamento; cartas nesta folha, com as iniciais S.B.".

Essencial à recuperação da saúde, a enfermagem préprofissional, inicialmente caritativa, foi sendo substituída, como desvelam os registros noticiosos, por uma representação autônoma, moderna e científica, fundada em teoria e métodos sistemáticos, que passaram a orientar a assistência. Nos anúncios de jornais, percebe-se, além do termo enfermeiro, a construção de um mercado de trabalho informal, mesmo sendo essas pessoas destituídas de qualquer conhecimento específico ${ }^{(3)}$.

\section{CONSIDERAÇÕES FINAIS}

Atualmente, o Brasil apresenta-se como um verdadeiro celeiro de profissionais de enfermagem, capacitados a atuar nos mais diferentes cenários de prática da saúde, chamados a trabalhar em vários países da Europa e nos Estados Unidos graças a sua competência técnica e legal. A enfermagem brasileira experimenta também um grande desenvolvimento em várias frentes de trabalho, relativo reconhecimento social e autonomia profissional. Porém, a primazia do exercício profissional da enfermagem brasileira não pode lograr esquecer suas origens, tampouco os que precederam à profissionalização do cuidado. Evocar a memória pré-profissional implica, nesse sentido, legitimar que o cuidado não acontece somente com a oficialização da formação profissional.

Assim, o presente estudo pretendeu dar o devido valor a essas figuras que, em seu tempo e lugar, souberam prestar cuidados necessários e dar alívio aos sofrimentos do próximo, realizando o que hoje constitui verdadeiramente o núcleo da enfermagem. Ainda que de forma intuitiva e sem o preparo hoje possível, aquelas pessoas exerceram efetivamente, com honestidade e desvelo, a arte de cuidar.

\section{Referências}

1. Collière MF. Promover a vida. Lisboa: Sindicato dos Enfermeiros Portugueses; 1989. 2. Oguisso T. Trajetória histórica e legal da enfermagem. 2ª ed. Barueri: Manole; 2007. 3. Araujo LA, Moreira A, Porto F, Amorim W. Anúncios para enfermeiros(as) no alvorecer da República. In: Porto F, Amorim W. História da enfermagem. São Caetano do Sul: Yendis; 2010. p. 21-53.

4. Machado de Assis JM. O enfermeiro. In: Machado de Assis JM. Várias histórias. 9a ed. São Paulo: Ática; 2000.

5. Moreira A, Oguisso T. Profissionalização da enfermagem brasileira. Rio de Janeiro: Guanabara-Koogan; 2005.

6. Santos Filho L. História da medicina no Brasil (do século XVI ao século XIX). São Paulo: Brasiliense; 1947. p. 24

7. Paixão W. Páginas da história da enfermagem. Rio de Janeiro: Universidade do Brasil; 1951.
8. Khoury YA. Guia dos arquivos das Santas Casas de Misericórdia do Brasil. São Paulo: Cedic/Fapesp; 2004.

9. Gandelman LM. Santa Casa de Misericórdia do Rio de Janeiro. Hist Cien Saúde. 2001;8(3):613-30.

10. Mattos W. D. Francisca de Sande (a primeira enfermeira do Brasil). Arq Público Bahia. 1949;31:368-420.

11. Rocha Pita S. História da América Portuguesa. Salvador: [s.n.]; 1878.

12. Costa A. Da Bahia a enfermeira número 1 do Brasil. JTarde. 07-05-1946.

13. Baggio H. Frei Fabiano de Cristo. Petrópolis: Vozes; 1974.

14. Souza Campos PF. Los negros y los cuidados en las familias de Brasil: una visión histórica e iconográfica. Cultura de los cuidados. Rev Enferm Human. 2008;(24):56-62. 15. Porto F, Oguisso T. Anna Justina Ferreira Nery. In: Porto F, Amorim W. Historia da enfermagem. São Caetano do Sul: Yendis; 2010. p. 1-19. 